\title{
Multi-Agent Framework for Social Customer Relationship Management Systems
}

\author{
Celina Olszak and Tomasz Bartuś \\ University of Economics in Katowice, Katowice, Poland
}

olszak@ue.katowice.pl; tomasz.bartus@ue.katowice.pl

\begin{abstract}
Social customer relationship management (CRM) systems have become an interesting research area for designers of management information systems. Designers have mainly concentrated on seeking the appropriate tools and technologies that would enable gathering, processing, analyzing and monitoring huge amounts of information in social media. Many previous tools and approaches used to design management information systems seem to be insufficient for social CRM systems. They need the technology and the approach based on modular design where modules (agents) specialize in solving a particular aspect of the problem and are able to interoperate and coordinate with each other in peer-to peer interactions.

The main purpose of this paper is to present an idea of social CRM, and first of all a multi-agent approach for designing and developing social CRM systems. This approach is to manage complex customer relationships in the world of social media. The agent technology provides an extension and alternative to customer relationship management with flexible and distributed features. In multi-agent approach, different activities are delegated to a number of autonomous agents. can gain many benefits beings as well as machines or software applications. Each of them has awareness of a particular situation and can make real-time decisions on different activities. To demonstrate this approach the prototype of a multi-agent social CRM system (MASCRM) is described. MASCRM uses the agent technology in the Facebook environment. The implementation of the prototype is explained and some results obtained are discussed.
\end{abstract}

The paper provides some valuable information on using a multi-agent approach for designing social CRM systems. The findings and outcomes should be useful for any designers of social CRM systems and for all organizations willing to use these systems.

Key words: customer relationship management (CRM), social CRM, agent technology, multiagent social CRM

\section{Introduction}

Material published as part of this publication, either on-line or in print, is copyrighted by the Informing Science Institute.

Permission to make digital or paper copy of part or all of these works for personal or classroom use is granted without fee provided that the copies are not made or distributed for profit or commercial advantage AND that copies 1) bear this notice in full and 2) give the full citation on the first page. It is permissible to abstract these works so long as credit is given. To copy in all other cases or to republish or to post on a server or to redistribute to lists requires specific permission and payment of a fee. Contact Publisher@InformingScience.org to request redistribution permission.
Customer relationship management (CRM) has become an interesting approach to management of a modern organization. It allows maintaining longterm relationships with customers, which results in e.g. increase in customer loyalty and profitability, and increased sales (Romano \& Fjermestad, 2002; Dyche, 2002; Payne \& Frow, 2005; Armstrong \& Kotler, 2004). 
The information about customers can be acquired from different places. These are usually internal databases, transaction systems and ERP (Enterprise Resource Planning) systems. Recently, social media have become a valuable source of information on customers. Social media including: Facebook, Twitter, MySpace, YouTube are used by customers to share their opinions about any products and services purchased. Exploration and analyses of such information may bring numerous benefits for organizations (e.g. more extensive knowledge of customers and satisfaction of their individual needs).

For many years, the key technologies used to build management information systems included: databases, data warehouse technology, data mining techniques, and on-line analytical processing techniques. They all are effective in processing data that come from structured, closed, internal databases and transaction systems (Olszak, 2012). However, these tools, turn out to be insufficient for collecting, processing, monitoring and analyzing data that originates from distributed and open information resources, such as social media.

The main aim of this paper is to describe the design and development of multi-agent social CRM system (MASCRM). The multi-agent approach provides a potential architecture and development methodology suitable for the dispersed information. MASCRM uses agent technology to address issues in the field of CRM, including integration of data originating from social media, reduced latencies and decision automation. To demonstrate the idea of MASCRM, a prototype that uses the agent technology in the Facebook environment is described. The implementation of this prototype is explained and some obtained results are discussed.

The structure of this paper is organized as follows: first, we provide an overview of the CRM concept, especially social CRM system. Then, we present agent technology that provides some foundation for the development of a social CRM system. Next, the MASCRM concept and its components are presented in detail followed with a description of the prototype system. Finally, we summarize the key points of the research and give directions for future research.

The results of this study may be useful for designers of social CRM systems, as well as for the organizations that plan to use social media in customer relationship management.

\section{Customer Relationship Management}

Customer relationship management is probably one of the most recognized management approaches of the past decade (Minna \& Aino, 2005). The increased competition, globalization, the development of information technology, total quality movement, system-selling approach and the development of network economy have had the significant influence on the prevalence of customer orientation (Parvatiyar \& Sheth, 2001).

For today's organization, the customers have become important resources, and relationships with them are considered valuable assets and investments (Gneiser, 2010). Effective customer relationship management has therefore become a priority task and an approach to management in many organizations (Armstrong \& Kotler, 2004). This results in improvement of customer satisfaction, increase in sales, customer profitability and loyalty (Kostojohn, Johnson \& Paulen, 2011).

The origins of CRM are strongly associated with the management concept of relationship marketing. The relationship marketing orientation is concentrating on building, developing and maintaining long-term relationships with customers, and other stakeholders (Levitt, 1983; Gummesson, 1987; Grönroos, 1990). It is an integrated effort to identify, build up and maintain a network with individual customers for the mutual benefit of both sides (Shani \& Chalasani, 1992). The key for acquiring and maintaining customers is to understand their preferences and to prepare a customizing offer (McKenn, 1991; Peppers, Rogers \& Dorf, 1999). In turn, CRM is a 
fusion of relationship marketing and management theories and approaches (Gummesson, 2002). It is concerned about managing relationships between a company and its customers with its all various contacts, interactive processes and communication elements (Grönroos, 2000). According to $\mathrm{Xu}$ et al. (2002) "CRM refers to an all-embracing management approach, which seamlessly integrates sales, customer service, marketing, field support, and other functions that touch customers". By providing information on customer data, profiles and history, CRM support an important area of a company's core processes, especially in marketing, sales and service (Ling \& Yen, 2001).

The growing importance of CRM is emphasized by numerous publications within the area of management and marketing. The overview of different description of the CRM topic is presented in table 1.

Table 1: The overview of description of CRM

\begin{tabular}{|c|c|}
\hline DESCRIPTION OF CRM & AUTHORS \\
\hline $\begin{array}{l}\text { CRM is a philosophy and a business strategy supported by a system and a } \\
\text { technology designed to improve human interactions in a business environment }\end{array}$ & (Greenberg, 2010) \\
\hline $\begin{array}{l}\text { The goal of CRM is not just to offer excellent products and services but to get, } \\
\text { keep and grow the best customers }\end{array}$ & $\begin{array}{l}\text { (Armstrong \& Ko- } \\
\text { tler, 2004) }\end{array}$ \\
\hline $\begin{array}{l}\text { CRM is an enterprise-wide approach to understanding and influencing custom- } \\
\text { er behavior through meaningful analysis and communications to improve cus- } \\
\text { tomer acquisition, customer retention, and customer profitability }\end{array}$ & $\begin{array}{l}\text { (Peppers \& Rogers, } \\
\text { 2004) }\end{array}$ \\
\hline $\begin{array}{l}\text { CRM is the core business strategy that integrates internal processes and func- } \\
\text { tions, and external networks, to create and deliver value to targeted customers } \\
\text { at a profit. It is grounded on high-quality customer data and enabled by IT }\end{array}$ & (Buttle, 2009) \\
\hline $\begin{array}{l}\text { CRM is the strategy for building, managing, and strengthening loyal and long- } \\
\text { lasting customer relationships. CRM should be a customer-centric approach } \\
\text { based on customer insight. Its scope should be the "personalized" handling of } \\
\text { customers as distinct entities through the identification and understanding of } \\
\text { their differentiated needs, preferences, and behaviors }\end{array}$ & $\begin{array}{l}\text { (Tsiptsis \& Choria- } \\
\text { nopoulos, 2009) }\end{array}$ \\
\hline $\begin{array}{l}\text { CRM helps improve the interfaces to customers and also aims at enhancing } \\
\text { customer satisfaction. CRM can therefore be defined as a customer-oriented } \\
\text { and IT-based management concept with the objective of establishing long-term } \\
\text { and profitable customer relationships }\end{array}$ & (Wilde, 2011) \\
\hline $\begin{array}{l}\text { CRM is an enterprise-wide business strategy for achieving customer-specific } \\
\text { objectives by talking customer-specific action. The firm will take customer- } \\
\text { specific actions for each customer, often made possible by new technologies }\end{array}$ & $\begin{array}{l}\text { (Peppers \& Rogers, } \\
\text { 2011) }\end{array}$ \\
\hline $\begin{array}{l}\text { CRM is a strategy of increased focus on developing, maintaining, and extract- } \\
\text { ing maximum value from customer relationships. CRM program includes peo- } \\
\text { ple, business process, and technology components }\end{array}$ & $\begin{array}{l}\text { (Kostojohn, Johnson } \\
\text { \& Paulen, 2011) }\end{array}$ \\
\hline CRM is a strategy to optimize lifetime value of customer & (Todman, 2001) \\
\hline $\begin{array}{l}\text { CRM is an interface connecting the organization with its customers, contrac- } \\
\text { tors and subcontractors }\end{array}$ & $\begin{array}{l}\text { (Parvatiyar \& Sheth, } \\
\text { 2001) }\end{array}$ \\
\hline $\begin{array}{l}\text { CRM aims at leveraging investments in customer relations to strengthen the } \\
\text { competitive position and maximize returns }\end{array}$ & (Bueren, et al., 2004) \\
\hline
\end{tabular}




\begin{tabular}{|l|l|}
\hline $\begin{array}{l}\text { CRM is understood as a customer-oriented management approach where in- } \\
\text { formation systems provide information to support operational, analytical and } \\
\text { collaborative CRM processes and thus contribute to customer profitability and } \\
\text { retention }\end{array}$ & $\begin{array}{l}\text { (Alt \& Puschmann, } \\
2004)\end{array}$ \\
\hline $\begin{array}{l}\text { CRM is a combination of business processes and technologies to effectively } \\
\text { understand the customers needs and immediately reflect them in the product } \\
\text { offer, and thus gain acceptance in the market, achieve customer satisfaction, } \\
\text { and create their loyalty }\end{array}$ & $\begin{array}{l}\text { (Davenport, Harris \& } \\
\text { Kohli, 2001) }\end{array}$ \\
\hline
\end{tabular}

Although the roots and the idea of CRM come from relationship marketing, CRM has had a very technical connotation (Fjermestad \& Romano, 2003; Xu, et al., 2002). Data warehouses, on-line analytical processing techniques and data mining techniques belong to the key technologies that are used to build CRM systems. Employing the above techniques CRM systems can facilitate gathering customer data, thus supporting customer service, sales and marketing by providing upto-date customer information and knowledge. The systems are also implemented to reduce the power of some staff group, particularly sales staff and sales agents (Roscoe, 2001). The adoption of CRM systems leads to redesigning customer-oriented processes, similar to the effect that ERP systems have had on production-oriented processes (Alt \& Puschmann, 2004).

Three different types of CRM systems are distinguished by several authors (Shanmugasundaram, 2010; Wilde, 2011; Peppers \& Rogers, 2011; Tuzhilin, 2012): operational, analytical, and collaborative. Recently, a concept of social CRM system has emerged.

An operational CRM system, called a front office CRM system (Buttle, 2009; Wilde, 2011), functions in the customer touching points by collecting customer data (Minna \& Aino, 2005). It supports marketing, sales and service departments through (Buttle, 2009):

- marketing automation, i.e. market segmentation, campaign management, and event-based marketing;

- sales force automation i.e. opportunity management, including lead management, contact management, proposal generation, product configuration;

- service automation i.e. contact and call-center operations, web-based service, field service.

An analytical CRM system, called a back-office CRM system, structures customer data into customer information (Minna \& Aino, 2005). It allows preparation of business analysis and operational reports (e.g. for sales, marketing research) and forecasts (e.g. for customer behavior, market). These analyzes provide a foundation for planning future sales strategies, marketing campaigns, identification of customer needs and behaviors and estimation of the costs of retaining and attracting customers (Buttle, 2009; Wilde, 2011). Analytical CRM uses such tools as: data warehouses, data mining, marketing and campaign analyses, clustering, and segmentation. Analytical CRM is recognized as an important element in the successful implementation of CRM in companies (Nykamp, 2001).

The main task of collaborative CRM is to improve the process of the organization's communication with customers, suppliers, and business partners in order to develop a long-term cooperation. To communicate (through customer interaction center, partner relationship management, and corporate portals), phones, SMS, e-mail and traditional mail, fax, and voice applications are used. Collaborative CRM is mainly used for direct communication with customers in the following departments: service (including technical assistance), sales (e.g. customer service center) and marketing (Kracklauer, Mills \& Seifert, 2004; Wilde, 2011).

Some authors also point to strategic CRM (Aurelie \& Laid, 2008; Payne \& Frow, 2005). This is linked to (or even identified) with the organization's business strategy, which is focused on devel- 
oping long-term relationships with customers (Buttle, 2009). Connection between different types of CRM systems is presented in Figure 1.

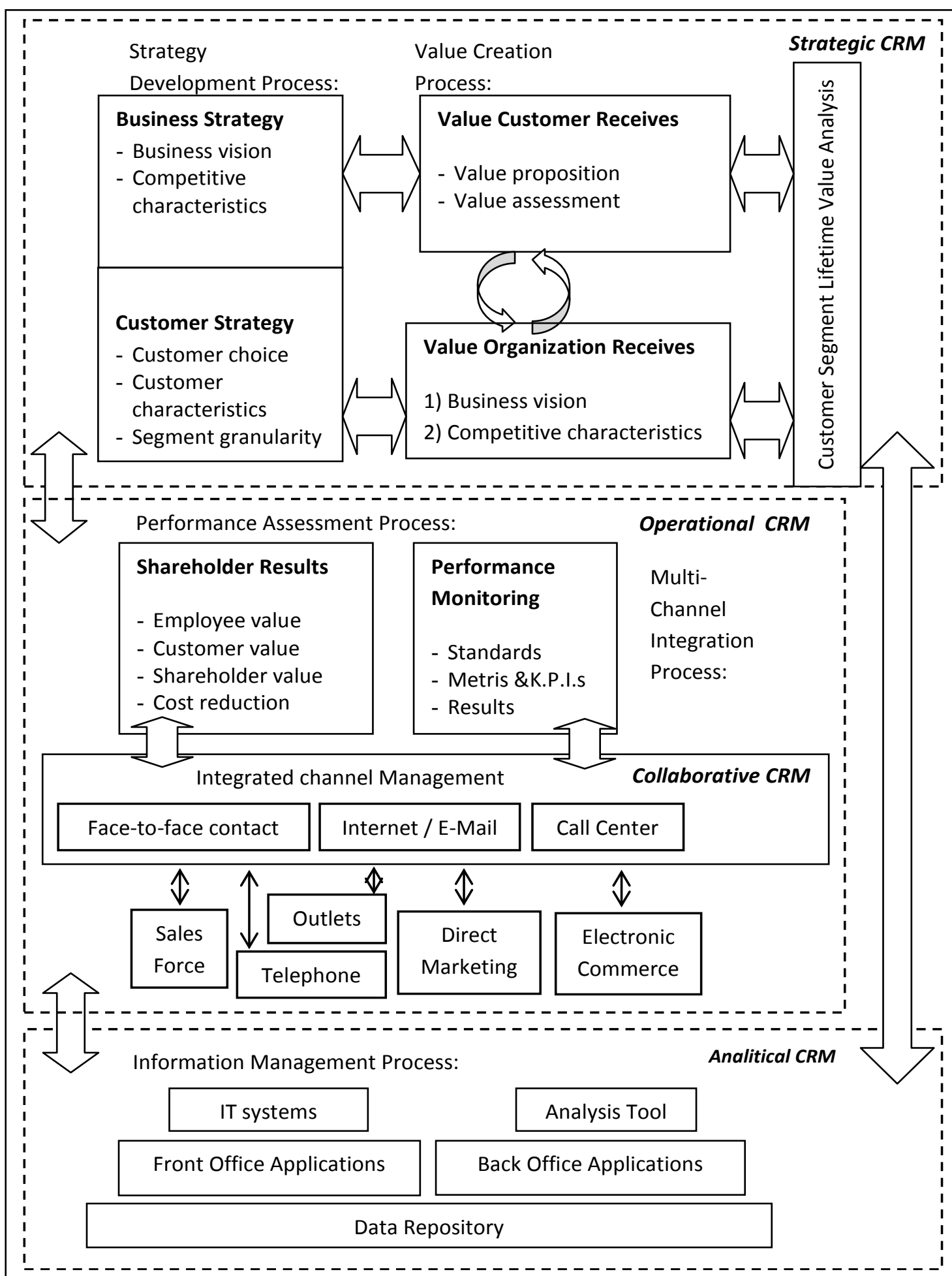

Figure 1: Relations among different CRM systems.

Source: Elaborated on (Aurelie \& Laid, 2008). 
It can be concluded that CRM systems can play a role of (Kostojohn, Johnson \& Paulen, 2011):

- a central repository of customer information, common to all employees;

- a platform to communicate with clients, that is responsible for the transmission of various information, documents, content to customers;

- Internet portal which allows customer service;

- an analytical center, that, on the basis of customers' profiles, may offer products, services the most appropriate to their needs.

\section{Social Customer Relationship Management}

Today's customers want to be active players in the market, they wish to maintain an open dialogue with various companies, have some impact on sales strategies and shape public opinion. Now, social media provide customers with these opportunities (Schaff \& Harris, 2012). Social media include such social tools and online services as: Facebook, Twitter, LinkedIn, YouTube, blogs, wiki, traditional and video sites. They allow different people to communicate, create, and share various content, as well as to search and connect with different people of similar interests and opinions (Halligan \& Shah, 2010; Greenberg, 2010). Popularization of social media means that customers can influence public opinion, share their satisfaction (or dissatisfaction) with products and services purchased. They can also be more effectively involved in the process of planning and designing products and services. This situation creates completely new tasks for marketing and public relations departments (Kostojohn, Johnson \& Paulen, 2011).

The inclusion of social resources in the customer relationship management is called social CRM or CRM 2.0. According to Greenberg (2010) "social CRM is a philosophy and a business strategy, supported by a technology platform, business rules, processes, and social characteristics, designed to engage the customer in a collaborative conversation in order to provide mutually beneficial value in a trusted and transparent business environment". In addition, Deloitte (2011) highlights that "social CRM paradigm adds to the traditional approach the building of the relationship and the knowledge of the customer by analyzing the bidirectional interactions (downwards and upwards) and horizontal, collaborative, community oriented ones, where the essential components are the experiences and emotions of users and communities".

Table 2 presents basic differences between CRM and social CRM.

Table 2: The Basic differences between traditional CRM and social CRM

\begin{tabular}{|l|l|l|}
\hline \multicolumn{1}{|c|}{ PARAMETERS } & \multicolumn{1}{c|}{ TRADITIONAL CRM } & \multicolumn{1}{c|}{ SOCIAL CRM } \\
\hline Roles & Customer service & All actors of the market engage \\
\hline Function & Process-centric & Conversation-centric \\
\hline Approach & Contact management & Community management \\
\hline Channel & Well-defined & Dynamic and evolving \\
\hline Value & Periodic connection with customer & Sustained customer engagement \\
\hline Model & Simple transactions & Complex relations \\
\hline
\end{tabular}

Source: (Paul \& Nilsson, 2011).

According to Paul and Nilsson (2011), organizations and customers, through the use of social CRM, can gain many benefits, such as:

- an organization can focus on community and building long-term relationships with them; 
- customers are the authors (owners) of content (posted on social networking sites) and keep control of their content;

- communication is not only business-to-customer type, but also the customer-to-customer and customer-to-prospectus;

- customers cooperate with the organization directly or indirectly in the development and improvement of products, services and customer support itself;

- dialogue is less formal and more "real", it changes its character from the conversation about the brand to talking about / to the community.

The idea of social CRM refers to the ability of the organization to meet customer's individual requirements, while achieving the goals set in the business plan. The main task of social CRM is to include customers in the activities of the organization, not to manage the customers. Specific differences between CRM approach and social CRM approach are presented in Table 3.

\section{Table 3: Specific differences between traditional CRM approach and social CRM approach}

\begin{tabular}{|c|c|c|}
\hline CRITERIA & $\begin{array}{l}\text { TRADITIONAL CRM AP- } \\
\text { PROACH }\end{array}$ & SOCIAL CRM APPROACH \\
\hline Content & $\begin{array}{l}\text { Focus on individual relationships } \\
\text { Messages are the value generators }\end{array}$ & $\begin{array}{l}\text { Focus on collaborative relationships } \\
\text { Conversations are the value generators }\end{array}$ \\
\hline Channels & $\begin{array}{l}\text { Single customer view, based on the } \\
\text { history of operations, stored in the } \\
\text { internal information systems }\end{array}$ & $\begin{array}{l}\text { This single view is harder to achieve, since } \\
\text { it includes the need to complement the in- } \\
\text { formation residing in internal systems with } \\
\text { profile information and behavior in social } \\
\text { networks }\end{array}$ \\
\hline Processes & $\begin{array}{l}\text { Customer service processes devel- } \\
\text { oped from the institution's stand- } \\
\text { point }\end{array}$ & $\begin{array}{l}\text { Customer service processes developed from } \\
\text { the customer's standpoint. }\end{array}$ \\
\hline Organization & $\begin{array}{l}\text { Innovation comes from one special- } \\
\text { ized source within the entity (inno- } \\
\text { vation team) }\end{array}$ & $\begin{array}{l}\text { Innovation is gathered from all the employ- } \\
\text { ees that are closely connected with the end } \\
\text { customers and among them via Web } 2.0 \\
\text { tools } \\
\text { Customers are in the center of the innova- } \\
\text { tion cycle }\end{array}$ \\
\hline Technology & $\begin{array}{l}\text { CRM solutions focused on automat- } \\
\text { ing and supporting internal business } \\
\text { processes }\end{array}$ & $\begin{array}{l}\text { Capture of network information in order to } \\
\text { know the customer in his social milieu }\end{array}$ \\
\hline $\begin{array}{l}\text { Communication } \\
\text { image and } \\
\text { brand reputa- } \\
\text { tion }\end{array}$ & $\begin{array}{l}\text { Massive face-to-face client commu- } \\
\text { nications depending on business } \\
\text { needs } \\
\text { Image and reputation analysis from } \\
\text { traditional market research }\end{array}$ & $\begin{array}{l}\text { Communication designed and supervised on } \\
\text { the basis of the analysis of structured infor- } \\
\text { mation involving the "social" traits of the } \\
\text { client } \\
\text { Image and reputation analysis from metrics } \\
\text { accounting for number of followers, type of } \\
\text { comment or impressions and influence on } \\
\text { the networks }\end{array}$ \\
\hline
\end{tabular}

Source: (Deloitt, 2011). 
To conclude, it should be stated that social CRM could be treated as a new business approach that extends the current capabilities of the traditional CRM, enabling an organization to have real time, conversations with its customers, to monitor customer's expression and to encourage them to constructive dialogue. However, the amount of information that need to be monitored, acquired, collected, processed, analyzed in the area of social media, often exceeds perceptual capabilities of workers. Designing of social CRM requires the tools that in an autonomous and intelligent way would explore and investigate comprehensive social resources. This idea can be achieved by the agent technology.

\section{Agent Technology}

The concept of the agent in information systems dates back to the seventies of the twentieth century, when studies on programs called "intelligent" were undertaken. The idea of an autonomous object - an interactive actor was presented in 1977 by Hewitt (1977). A new trend of research on agents appeared around 1990 and it concerned the development of the theory and design of architectures of different types of agents, as well as the ability to communicate between them (Nwana, 1996).

It is noted that although "agent" is frequently defined in the literature, there is no universal explanation of "agent" term. It is often associated with the following notions: intelligent agent, intelligent software, wizards, knowbots, taskbot, userbot, software agent, softbots-intelligent, or software robots. According to Hewitt (1977) an agent is an interactive object basing on parallel processing, having some internal state and the ability to respond to messages of other objects (actors).

The agent is an entity that performs some actions in a particular environment and is aware of the emerging changes. Moreover, it can react to such changes (Poole \& Mackworth, 2010). The agent has a set of goals, certain capabilities to perform actions, and some knowledge (or beliefs) about its environment (Wang \& Wang, 2005). In addition, Thomsen (2002) describes the agent as "a solution-oriented ensemble of capabilities including natural language processing, autonomous reasoning, proactive computing, discourse modeling, knowledge representation, action-oriented semantics, multimodal interaction, environmental awareness, self awareness, and distributed architectures". IBM (2012), in turn, defines intelligent agents as "software entities that carry out some set of operations on behalf of a user or another program, with some degree of independence or autonomy, and in so doing, employ some knowledge or representation of user's goals and desires".

Many authors emphasize the specific properties of the agents. They include (Franklin \& Graesser, 1996; Wooldridge, 1997; Wooldridge \& Jennings, 1995; Wooldridge, 2009; Sterling \& Taveter, 2010; Bartuś, 2012, Bellifemine, Caire \& Greenwood, 2007; Poole \& Mackworth, 2010):

- autonomy - the autonomy means that the agent operates as an independent process, with no direct human intervention and has control over its actions and internal state;

- reactivity - the agent perceives its environment and promptly answers to the perceived environment changes;

- pro-activity - the agent not only reacts to its environment changes, but is able to manifest a goal oriented behavior, and take the initiative;

- social ability - the agent is able to interact with other agents or humans, using an agent communication language;

- self-analysis - the agent is capable of analyzing and explaining its behavior and of detecting its errors or its success;

- learning - adaptation and improvement by interaction with its environment; 
- temporally continuous - the agent it runs continuously in its environment, as long as necessary to implement the task;

- mobile - the agent it has an ability to move between different environments.

Other properties sometimes mentioned in the context of agents include (Rudowsky, 2004):

- mobility - the ability to move around any electronic environment;

- veracity - the agent will not knowingly communicate false information;

- benevolence - the agents do not have conflicting goals and every agent will therefore always try to do what they are instructed;

- rationality - the agent will act in order to achieve its goals insofar as its beliefs permit.

A BDI (Belief, Desire, Intention) model is one of the most known models that is used for programming the agents. The model consists of three components (Bellifemine, Caire \& Greenwood, 2007; Chang-Hyun \& Einhorn, 2005; Oijen, van Doesburg \& Dignum, 2011):

- Belief - represents the informational state of the agent (including itself and other agents). It may include rules of requesting, which leads to the new beliefs formation;

- Desire/Goal - reflects agent's motivation state. The examples of desires might be: find the best price, best customer;

- Intention/Plan - means that the agent starts to perform an action plan. Plans are sequences of the actions that the agent can perform in order to achieve one or more of its goals.

It has already been pointed out that the capacity of an intelligent agent is limited by its knowledge, its computing resources, and its perspective (Simon, 1957). Therefore, it is required forming communities (agency) of agents. These communities, based on a modular design, can be implemented, where each member of the agency specializes in solving a particular aspect of the problem. The agents must be able to interoperate and coordinate with each other in peer-to-peer interactions (Rudowsky, 2004). This idea of the agents operation is nowadays described as a multi-agent system. A multi-agent system can be defined as a loosely coupled network of entities that work together to solve a problem that cannot be solved by an individual agent. These entities can show self-organization and complex behavior, even if the individual agent's strategies are simple (Bologa \& Bologa, 2011). Multi-agent system is a network of agents that are reasoning (problem solvers) and cooperating, communicating and negotiating to achieve a specific task. Individual agents are able to adapt their behavior to the changing environment in which they work (Weyns, 2010). Agents are usually attributed with such characteristics as: adaptability, openness, stability and scalability (Weyns, 2010; Bordini, Hübner \& Wooldridge, 2007). When characterizing a multi-agent system, it is stressed that (Sycara, 1998; Weyns, 2010):

- each agent has incomplete information or capabilities for solving the problem and, thus, has a limited viewpoint;

- there is no global control system;

- data is decentralized;

- computation is asynchronous.

A good example of agents' co-operation is a teamwork in which a group of autonomous agents cooperate, both to develop their own individual goals, as well as for the good of the whole system (Ferber, 1999; Lesser, Abdallah, 2007; Bellifemine, Caire \& Greenwood, 2007).

The following characteristics of the agent technology lead to the conclusion that this technology can be widely used in business. Particularly, it provides some extension and alternative to customer relationship management with flexible, distributed, and intelligent features. 


\section{Design of a Multi-Agent Model for Social CRM}

A model and a prototype of a system, called a multi-agent social CRM (MASCRM), was developed in order to demonstrate the use of a multi-agent approach for designing and developing a social CRM system. It was assumed that MASCRM should be flexible enough to allow: (1) automatic acquisition and processing of various data originating from social media, (2) optimization of individual agents tasks, (3) transfer of the collected data, not only to the data base of social CRM, but also to other information systems, (4) further development of the system (adding more agents), and (5) integration of the system with other information systems.

The MASCRM features have been determined by the following factors:

- social media are dynamic and they are characterized by a constant flow of different data (text and multimedia);

- there are important differences between specific social media: blogs (such as Blip, Twister), content communities (e.g. YouTube, Vimeo, Wikipedia), resources provided by the users (e.g. blog, wiki, social networking sites). This implies some need to use different methods of data acquisition by multi-agent system;

- work with social media takes place in several stages. First, specific Web pages and data on these pages are searched, then the acquired content is cleaned and filtered, and finally stored in a data repository;

- $\quad$ social platforms are not integrated with CRM systems.

MASCRM consists of two groups of modules: (1) monitoring and capturing agents, (2) analytical agents. The first group of agents is responsible for monitoring and collecting data on users (mainly customers, competition) from social media. It also plays a role of an interface between social media and other information systems of the organization. The latter group of agents is responsible

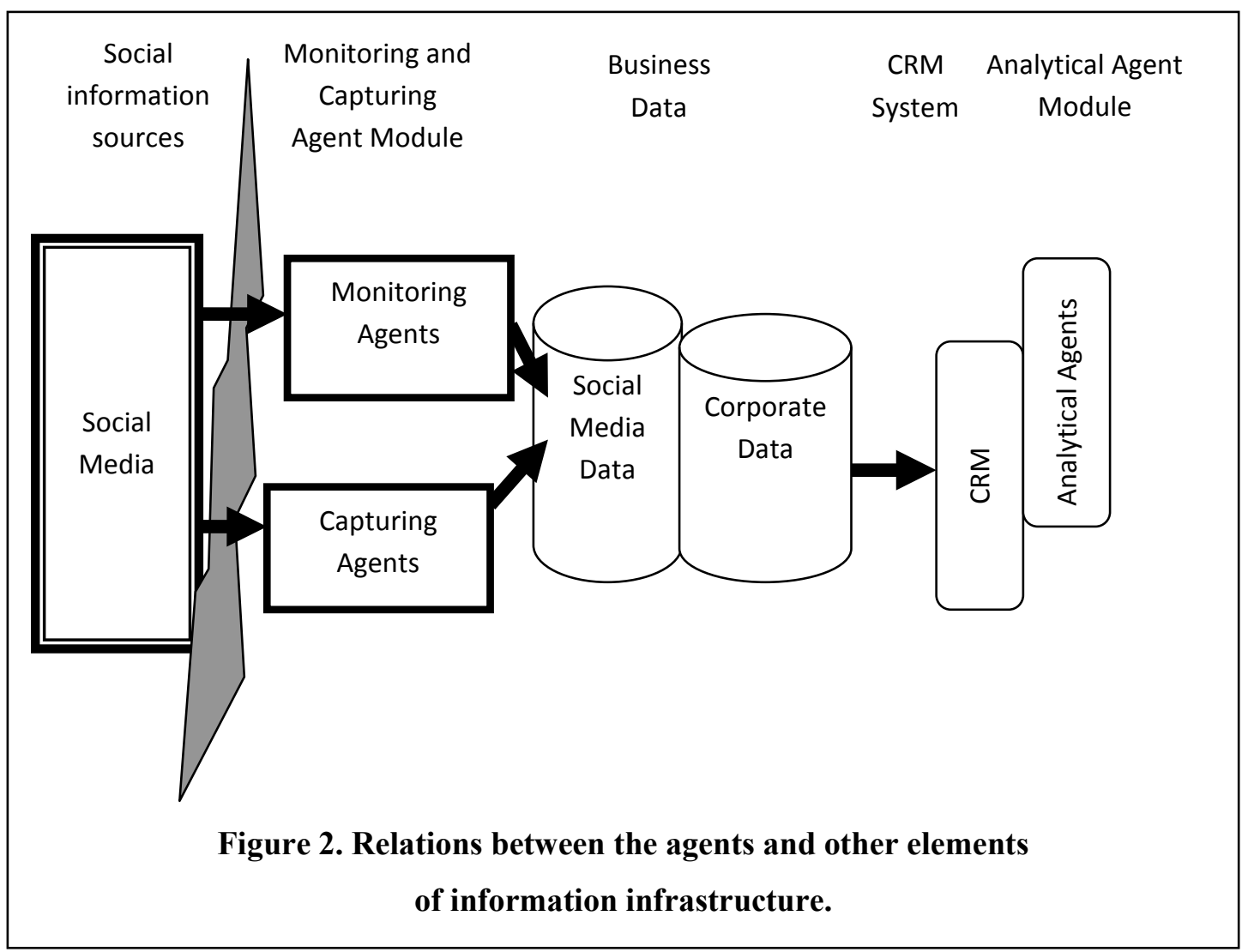




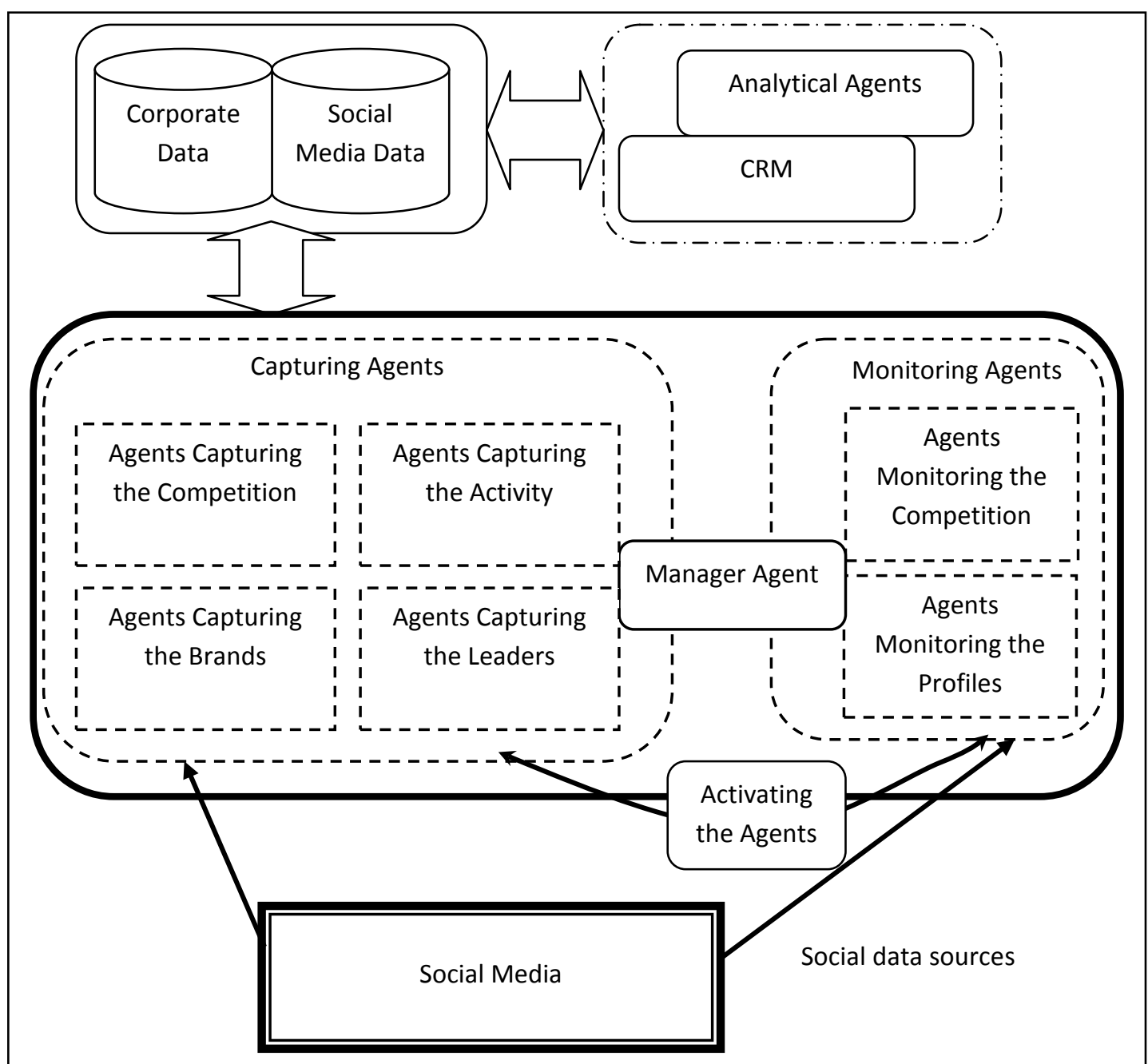

Figure 3. The frame of MASCRM system

for performing various analyzes of customers (e.g., segmentation, customer behavior, customer loyalty etc.). Figure 2 shows the relations between the agents and other elements of the information infrastructure of the organization.

A single agent in MASCRM is attributed with functions, rules and methods to work in the specific domain (monitoring, capturing, analyzing). Individual agents are autonomous entities, i.e. they may work independently or collaborate with other agents.

The framework of MASCRM includes the following elements (Figure 3): Monitoring Agents (MA), Capturing Agents (CA), the Agent Manager (AM), Social Media Data (SMD), Analytical Agents (AA).

\section{Monitoring Agents}

The purpose of Monitoring Agents (MA) is to monitor the activity of different users (including customers and competitors) on social networking sites, forums, wikipedia, blogs and online auc- 
tions. This group of agents includes: Agent Monitoring the Competition (AMC) and Agent Monitoring the Activity (AMA) of other users, including customers and suppliers.

The aim of Agent Monitoring the Competition is to track the competition by identifying any content on its social media (e.g. content and opinions on social media sites, files, links). List of competitors is defined in MASCRM. Monitoring the social resources can run continuously or can be carried out in accordance with a specific timetable. When AMC detects new content posted in social media by the competitors, it sends a signal that activates the Capturing Agent. At this point, it starts acquiring new contents from a particular social media user profile. Then, Agent Monitoring the Competition saves the data on the competition's activity in social media data. This data is mainly:

- the competition's identifier (login, a full description of the name of competition, e.g. the company name, a link to the social profile);

- characteristics of the competition's activity, relating to: the date and time of detecting the activity, area of activity;

- status, the date and time of activation of the agent for capturing information about the competition.

Finally, Agent Monitoring the Competition checks in the schedule whether it should still work or go into a so-called "sleep" mode.

The task of Agent Monitoring the Activity (AMA) is to monitor specific social media for the activity of other users (mainly customers, suppliers). AMA identifies the users' activity on the chosen social media profiles and stores information on this activity in social media data. Similarly to Agent Monitoring the Competition, AMA can work on the basis of a predetermined schedule. When Agent Monitoring the Activity detects updating or adding new information to the user's profile, it sends a signal that activates Agent Capturing the Profiles. At this point, the agent starts acquiring new contents from a particular user profile. Then, Agent Monitoring the Activity saves the data on activity of specific social profiles users in a social media data. This data is mainly:

- identifier of a social profile user (login, full description, link to the social profile, user name e.g. first and last name);

- characteristics of the activity, relating to: the date and time of detecting/appearing of activity on the social profile, area of activity;

- status, the date and time of activation of Agent Capturing the Profiles.

Finally, Agent Monitoring the Activity checks whether it should still work or go into a so-called "sleep" mode. Mostly text mining and web mining techniques were used for work of the described agents.

\section{Capturing Agents}

The task of Capturing Agents (CA) is to search and collect important information about the users of social media. They mostly acquire certain keywords, phrases or files. This group of agents includes:

- Agent Capturing Information about Competition (ACC) - acquires, stores and processes information from social media about the competition;

- Agent Capturing Information about User Profiles (ACUP) - acquires, stores and processes information about profiles of customers, suppliers and contractors; 
- Agent Capturing Information about Brands, Products, and Services (ACBPS) - acquires, stores and processes information on opinions about the organization, its brand, products, services, customer service, etc.;

- Agent Capturing Information about Social Leaders (ACSL) - identifies the profiles of social leaders (e.g. the most active "fans," customers), and then acquires, stores and processes information about them (e.g. the number of their activities in relation to the average number of other users activity).

Capturing Agent acts as a kind of integrator of social media, Social Media Data (SMD) and business data. The exchange of information between the various modules of the MASCRM system is performed by data files stored in XML format. Data obtained by the different types of Capturing Agent is stored in social media data.

\section{Manager Agent}

Manager Agent is responsible for reliability of the whole system, and manages the operation of the individual agents, especially the agents monitoring and capturing the contents from social media.

\section{Social Media Data}

Social Media Data (SMD) is a repository where the data acquired by individual agents is stored. This repository is a valuable source to load the data warehouse and CRM system. The figure 4 presents the content for SMD.

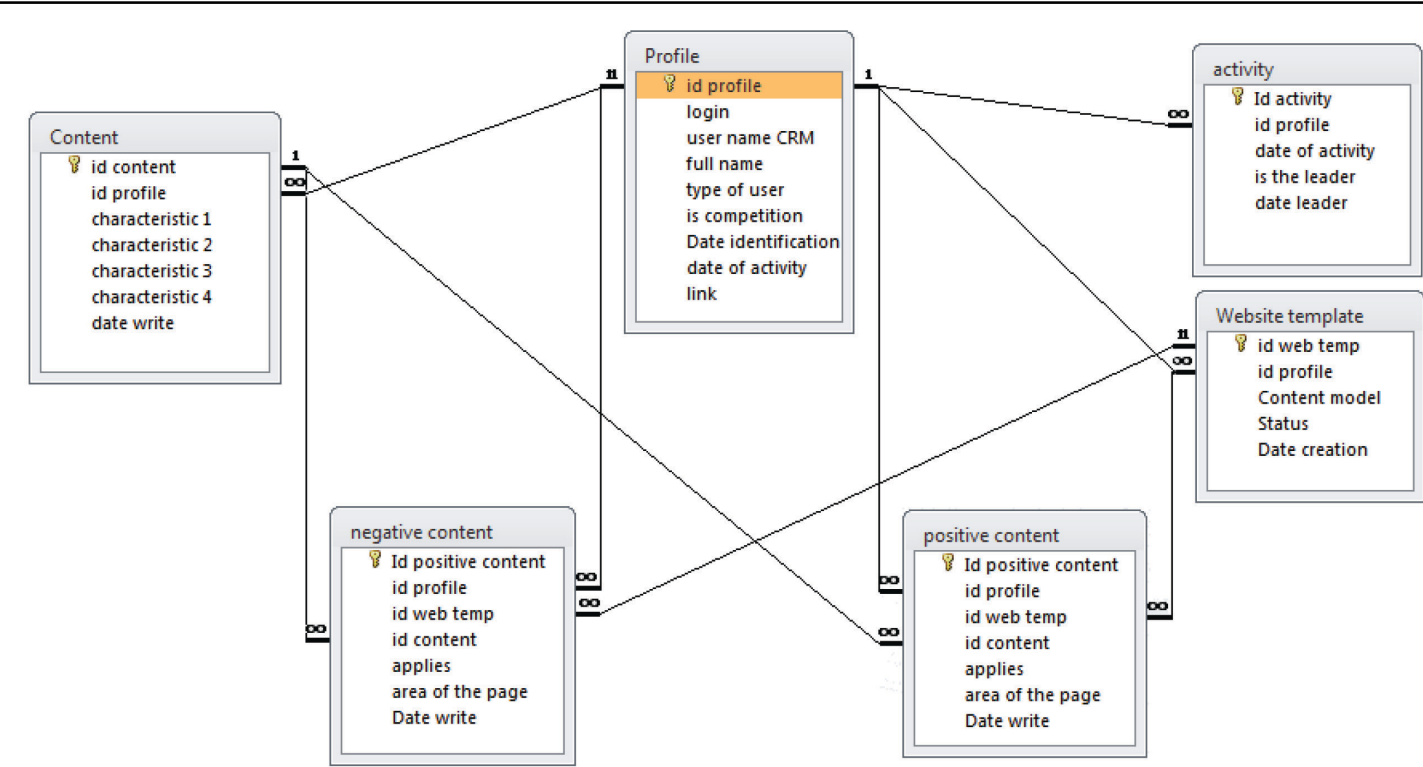

Figure 4. Social Media Database schema

\section{Analytical Agents}

Analytical agents are the last group of agents in MASCRM system. These are:

- product agent, responsible for forecasting the position of the brand or product in the market;

- segmentation agent, responsible for dividing the customers according to various criteria (e.g. profitable or loyal customers); 
- purchase agent, carrying out analysis on products purchased and performing appropriate market basket analysis;

- promotional agent, responsible for sending offers, advertising campaigns to relevant customers and suppliers;

- social media agent, carrying out analysis on customers' opinions, marketing activities;

- user agent, responsible for drawing up the characteristics of the groups / segments of users, forecasting customer behavior;

- $\quad$ analysis and reports agent (social analysis, social reports), responsible for preparing summary statements and reports on sales, users activity, their loyalty, changes in behavior and preferences.

\section{Case Study Description and Discussion}

MASCRM prototype was implemented in Facebook. Two groups of agents were tested and verified:

- Agents Monitoring Facebook, including Agent Monitoring the Competition (AMC) and Agent Monitoring the Activity (AMA) of other users (customers, suppliers);

- Agents Capturing Information on Facebook, including: Agent Capturing Information about the Competition (ACC), Agent Capturing the Profile (ACP), Agent Capturing Information about Brands, Products, and Services (ACBPS), and Agent Capturing Information about Social Leaders (ACSL).

The implementation of these agents in Facebook required the following analysis: (1) the type/ category/format of data, which can be found in various social media, (2) possibilities of using this data (3) who is the author of the data, (4) who is the recipient of the data (what user will use them, to what analysis/business processes they can be used), (5) methods of data acquisition, (6) methods of data analysis, (7) methods of data interpretation.

The implementation of MASCRM needed the building:

- user model (login: user data, "favorite sites" - including business, "friends list" - including business; discussion groups, profile walls with the content; activity - the date: when, how often; area: product, information on the company, content: keywords);

- $\quad$ social media leader model (login: user data, "favorites" - including business, friends - including business; activity - the date: when, how often; area: product, company information; content: keywords; the number of entries / total activity / compared to other users);

- brand / product / service awareness model (opinion - positive / negative, number of reviews, author / opinion segment, social media name);

- competitor model (login, activity - date, area, content);

- model of the flow of information between the agents and the data repository (social media data);

- model of access to the data stored in social media data.

The MASCRM implementation was carried out in three stages based on:

- configuration of the individual agents;

- activation of individual agents;

- $\quad$ storage of information (acquired by individual agents) in the social media base.

Figure 5 presents the diagram for MASCRM. 


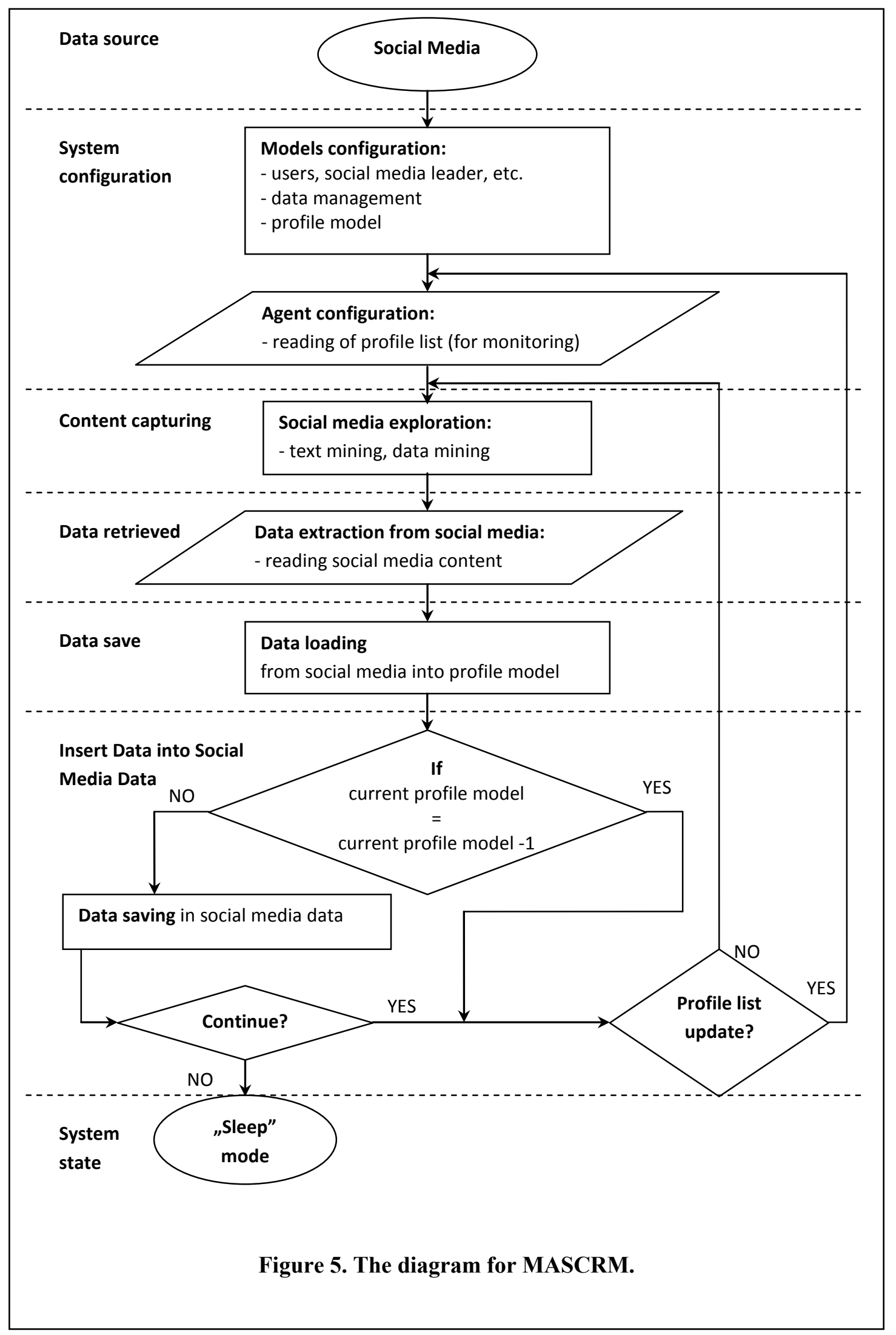




\section{Agents Configuration}

The first stage of the MASCRAM implementation turned out to be the most difficult. This was mainly related to the configuration of individual agents.

Configuration of Agent Monitoring the Competition (AMC) on Facebook consisted of:

- planning the agent's work schedule (the activity time, "sleep" mode);

- updating the database containing profiles of competition;

- monitoring (checking periodically) the correctness of the data acquired by the agent.

The configuration of Agent Monitoring the Activity (AMA) of Facebook users was proceeded in a similar manner. It consisted of:

- planning the agent's work schedule;

- updating the database containing profiles of the users defined e.g. as the organization's "fans," loyal customers;

- monitoring the correctness of the data acquired by the agent.

The configuration of Agent Capturing Information about Competition (ACC) on Facebook was associated with:

- planning the agent's work schedule. The monitoring agent can activate the capturing agent at any time, if necessary;

- updating the database containing profiles of the competition;

- monitoring the correctness of the data acquired by the agent.

The configuration of Agent Capturing Information about the Profiles (ACP) on Facebook required:

- planning the agent's work schedule. The monitoring agent can activate the capturing agent at any time, if necessary;

- updating the database containing user profiles;

- monitoring the correctness of the data acquired by the agent.

The configuration of Agent Capturing Information about the Brand, Products, and Services (ACBPS) on Facebook consisted of:

- planning the agent's work schedule. The monitoring agent can activate the capturing agent at any time, if necessary;

- updating the database containing information about the brand, products, services;

- monitoring the correctness of the data acquired by the agent.

The Agent Capturing Information about the Social Leader (ACSL) on Facebook was configured according to the following rules, i.e.:

- planning the agent's work schedule. The monitoring agent can activate the capturing agent at any time, if necessary;

- updating the database storing information about social leaders;

- monitoring the correctness of the data acquired by the agent.

\section{Activating the Work of Individual Agents}

The individual agents are autonomous and carry out their tasks in accordance with a predetermined schedule (plan). At any time, however, they may be activated by other agents. The work of the individual agents is mainly focused on the constant comparison of data (on Facebook) with the data contained in social media data and its appropriate modifications. 


\section{Saving Information in Social Media Base}

The data collected by individual agents is saved in the working database. Then, it is integrated in the social media data. Social media data is the primary source that is used to load the CRM data warehouse.

\section{Evaluation of MASCRM Implementation}

Summing up MASCRM system implementation, carried out in Facebook, it should be noted that the complexity of the actions undertaken and their often highly technical nature, resulted in the fact that all of the issues could not be presented in a comprehensive manner. We have tested MASCRM system in the scope of agents monitoring and capturing information on Facebook. The implementation of analytical agents in Facebook is a challenge that we wish to face in the near future. Regardless of this fact, we can now make an initial evaluation of the MASCRM system. We notice both its advantages and disadvantages. Undoubtedly, among the MASCRM strengths there are:

- system flexibility allowing to extract data from any social media;

- fast extraction of data on a selected social media profile;

- reduction of work resources (time, specialists) while acquiring, filtering, processing and sharing information from social media;

- providing the organizations with relevant information (directly from customers) about their interests, preferences.

The functionality of the agents implemented in MASCRM system gives an opportunity for:

- early identification of customers social attitudes, and an appropriate response to them;

- MASCRM co-operation with other agent systems;

- providing the organizations with valuable information necessary to build the brand and public relations.

When testing the MASCRAM system in Facebook, we also noticed its weaknesses. These are mostly:

- complex process of development, software and configuration of the agent system;

- the need to monitor and check the accuracy of the individual agents work, especially in the early stages of their work;

- the need to redesign the work of individual agents when changing the structures of Web pages;

- unexpected server and ICT infrastructure downtime can destabilize the work of individual agents.

\section{Conclusion}

The main conclusion of this study is reflected in the statement that multi-agent approach is an interesting and useful method of SCRM designing. A developed and tested MASCRM system is an autonomous application consisting of a group of agents that independently acquire a number of important data necessary to manage the customer relationship. Agents are also able to communicate with each other and activate mutually. MASCRAM system can work with a variety of social media, not only with Facebook. It is able to collect a lot of data on the customers behavior, their purchase preferences, etc. The organizations can quickly respond to the opinions and attitudes of their current and future customers, and also quickly assess the relevance of their marketing actions and decisions. In conclusion, we need to emphasize that the developed MASCRM system 
needs to be further verified and tested. Finally, MASCRM system should also include analytical agents. Their development is the authors' future plan.

The study has made a theoretical contribution to social CRM systems. The outcomes extend current theory on designinig and developing of social CRM systems based on multi-agent approach. They provide useful information, which hopefully will encaurage the organizations to use social CRM systems.

\section{References}

Alt, R., \& Puschmann, T. (2004). Successful practices in customer relationship management. Proceedings of the 37th Hawaii International Conference on System Science.

Armstrong, G., \& Kotler, P. (2004). Marketing: An introduction. Upper Saddle River: Prentice Hall.

Aurelie, D., \& Laid B. (2008). The alignment between customer relationship management and IT strategy. Proceedings of the Southern Association for Information Systems Conference, Richmond, USA.

Bartuś, T. (2012). Intelligent agents in customer relationship management. Proceedings on IT for Practice, VSB-TU, Ostrava, 1-11.

Bellifemine, F., Caire, G., \& Greenwood, D. (2007). Developing multi-agent systems with JADE. Chichester: John Wiley \& Sons Ltd.

Bologa, A., \& Bologa, R. (2011). Business intelligence using software agents. Database Systems Journal, 2(4), 31-42.

Bordini, R., Hübner, J., \& Wooldridge, M. (2007). Programming multi-agent systems in AgentSpeak using Jason. New York: John Wiley \& Sons Ltd.

Bueren, A., Schierholz, R., Kolbe, L., \& Brenner, W. (2004). Customer knowledge management Improving performance of customer relationship management with knowledge management. Proceedings of the 37th Hawaii International Conference on System Sciences.

Buttle, F. (2009). Customer relationship management. Oxford: Butterworth-Heinemann.

Chang-Hyun, J., \& Einhorn, J. M. (2005). A BDI agent-based software process. Journal of Object Technology, 4(9), 101-121.

Davenport, T. H., Harris, J. G., \& Kohli, A. K. (2001). How do they know their customers so well? MIT Sloan Management Review, 42(2), 63-73.

Deloitte. (2011). CRM 2.0 or social CRM for financial industry. Retrieved on 15 September 2012 from http://www.deloitte.com/assets/DcomCroatia/Local\%20Assets/Documents/2012/FSINews03.02Social CRM.pdf

Dyche, J. (2002). Handbook: A business guide to customer relationship management. Boston: AddisonWesley.

Ferber, J. (1999). Multi-agent systems: An introduction to distributed artificial intelligence. Boston: Addison - Wesley Longman.

Fjermestad, J., \& Romano, N., Jr. (2003). Electronic customer relationship management: Revisiting the general principles of usability and resistance - An integrative implementation framework. Business Process Management Journal, 9(5), 572 - 591.

Franklin, S., \& Graesser, A. (1996). Institute for intelligent systems. Memphis: University of Memphis Press.

Gneiser, M. (2010). Value-based CRM. Business \& Information Systems Engineering, 2(2), 95-103.

Greenberg, P. (2010). CRM at the speed of light. Social CRM strategies, tools, and techniques for engaging your customer. New York: McGraw-Hill. 
Grönroos, C. (1990). Relationship approach to marketing in service contexts: The marketing and organizational behavior interface. Journal of Business Research, 20(1), 3-11.

Grönroos, C. (2000). Service management and marketing - A customer relationship management approach. New York: John Wiley \& Sons Ltd.

Gummesson, E. (1987). The new marketing - Developing long-term interactive relationships. Long Range Planning, 20(4), 10 - 20.

Gummesson, E. (2002). Relationship marketing in the new economy. Journal of Relationship Marketing, $1(1), 37-55$.

Halligan, B., \& Shah, D. (2010). Inbound marketing get found using google, social media, and blogs. New Jersey: John Wiley \& Sons Ltd.

Hewitt, C. (1977). Viewing control structures as patterns of passing messages. Artificial Intelligence, 8(3), 323-364.

IBM (2012). IBM's intelligent agent strategy. White paper. Retrieved on 15 September 2012 from http://activist.gpl.ibm.com:81/WhitePaper/ptc2.htm.

Kostojohn, S., Johnson, M., \& Paulen, B. (2011). CRM fundamentals. New York: Apress.

Kracklauer, A., Mills, D., \& Seifert, D. (2004). Collaborative customer relationship management: Taking CRM to the next level. Berlin Heidelberg: Springer-Verlag.

McKenn, R. (1991). Relationship marketing: Successful strategies for the age of the customer. Cambridge: MA Perseus Books.

Lesser, V., \& Abdallah, S. (2007). Multiagent reinforcement learning and self-organization in a network of agents. AAMAS 07, Honolulu, Hawaii, ACM.

Levitt, T. (1983). After the sale is over. Harvard Business Review, 63(5), 87-93.

Ling, R., \& Yen, D. C. (2001). Customer relationship management: An analysis framework and implementation strategies. Journal of Computer Information Systems, 41(3), 81-97.

Minna, R., \& Aino, H. (2005). Customer knowledge management competence: Towards a theoretical framework. Proceedings of the 38th Hawaii International Conference on System Sciences.

Nykamp, M. (2001). The customer differential: The complete guide to implementing customer relationship management. New York: Amacom.

Oijen, J., van Doesburg, W. A., \& Dignum, F. (2011). Goal-based communications using BDI agents as virtual humans in training: An ontology driven dialogue systems. In J. Dignum (Ed.), Agents for games and simulations II (pp. 38-52). Berlin Heidelberg: Springer-Verlag.

Olszak, C. M. (2012). Competing with business intelligence. Proceedings on IT for Practice, VSB-TU, Ostrava, 98-108.

Parvatiyar, A., \& Sheth, J. (2001). Customer relationship management: Emerging practice, process, and discipline. Journal of Economic and Social Research, 3(2) 1-34.

Paul, A., \& Nilsson, J. (2011). Social CRM. Chichester: John Wiley \& Sons Ltd.

Payne, A., \& Frow, P. (2005). A strategic framework for customer relationship management. Journal of Marketing, 69(4), 167-176.

Peppers, D., \& Rogers, M. (2011). Managing customer relationships: A strategic framework. New Jersey: John Wiley \& Sons Ltd.

Peppers, D., \& Rogers, M. (2004). Managing customer relationships: A strategic framework. New Jersey: John Wiley \& Sons Ltd.

Peppers, D., Rogers, M., \& Dorf, B. (1999). Is your company ready for one-to-one marketing. Harvard Business Review, 77(1), 151-160. 
Poole, D., \& Mackworth, A. (2010). Artificial intelligence: Foundations of computational agent. Cambridge: University Press.

Romano, N. C., \& Fjermestad, J. (2002). Electronic commerce customer relationship management: An assessment of research. International Journal of Electronic Commerce, 6(2), 61-113.

Roscoe, D. (2001). The customer knowledge journey. Journal of Database Marketing, 5(4), 314 - 318.

Rudowsky, I. (2004). Intelligent agents. Proceedings of the Americas Conference on Information Systems, New York.

Russell, S., \& Norvig, P. (2003). Artificial intelligence: A modern approach. New Jersey: Prentice Hall.

Schaff, C., \& Harris, G. (2012). 7 secrets to social media business success. Retrieved on 10 September 2012 from http://www.prnewsonline.com/Assets/File/digitalpr presentations2012/Clinton Schaff.pdf

Shani, D., \& Chalasani, S. (1992). Exploiting niches using relationship marketing. The Journal of Consumer Marketing, 9(3), 33-42.

Shanmugasundaram, S. (2010). Customer relationship management: Modern trends and perspectives. PHI Learning Pvt. Ltd.

Simon, H. (1957). Models of man: Social and rational-Mathematical essays on rational human behavior in a social setting. New York: Wiley.

Sterling, L., \& Taveter, K. (2010). The art of agent-oriented modeling. London: The MIT Press Cambridge.

Sycara, K. P. (1998). Multiagent systems. Artificial Intelligence Magazine, 19(2), 79-92.

Thomsen, E. (2002). Agents uncovered. Intelligent Enterprise, 5(15), 45.

Todman, C. (2001). Designing a data warehouse: supporting customer relationship management. Upper Saddle River: Prentice Hall.

Tsiptsis K., \& Chorianopoulos, A. (2009). Data mining techniques in CRM inside customer segmentation. Chichester: John Wiley \& Sons Ltd.

Tuzhilin, A. (2012). Customer relationship management and Web mining: the next frontier. Data Ming Knowledge Discovery, 24(3), 584-612.

Wang, M., \& Wang, H. (2005). Intelligent agent supported business process management. Proceedings of the 38th Hawaii International Conference on System Sciences.

Weyns, D. (2010). Architecture-based design of multi-agent systems. Berlin Heidelberg: Springer-Verlag.

Wilde, S. (2011). Improving customer relationship through knowledge application. Berlin Heidenberg: Springer-Verlag.

Wooldridge, M., \& Jennings, N. (1995). Intelligent agents. Theory and practice. Knowledge Engineering Review, 10(2), 115-152.

Wooldridge, M. (1997). Agent-based software engineering. IEE Proceedings on Software Engineering, 144 (1), 26-31.

Wooldridge, M. (2009). An introduction to multi agent systems. New York: John Wiley \& Sons Ltd.

Xu, Y., Yen, D., Lin, B., \& Chou, D. (2002). Adopting customer relationship management technology. Industrial Management \& Data Systems, 102(8), 442-452. 


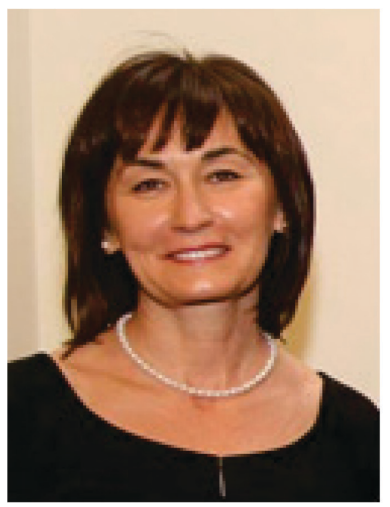

\section{Biographies}

Celina M. Olszak is a professor of Management Information Systems and a chair at of the Department of Business Informatics at the University of Economics in Katowice, Poland. DAAD and Swiss Government scholarship holder. The author of 10 books and over 150 academic journal articles. Her research and teaching focuses on decision support systems, business intelligence, management information systems and information society. She is a member of Polish Academy of Sciences and Informing Science Institute in California, USA.

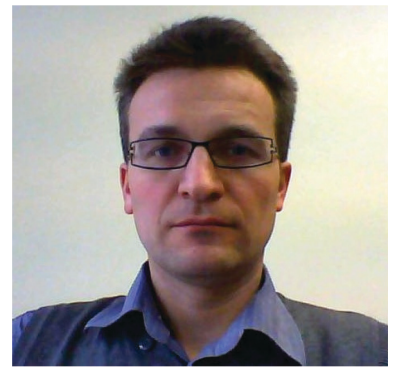

Tomasz Bartuś is a doctor of Management Information Systems. He received his Ph.D. from the University of Economics in Katowice, Poland. His research and teaching focuses on customer relationship management, management information systems, Internet technologies, programming languages and techniques. 